\title{
Decolourization of Azo (Acid Red) and Anthraquinonic (Basic Blue) Dyes by the Fungus Aspergillus flavus
}

\author{
Lokendra Singh ${ }^{1, *}$, Ved Pal Singh ${ }^{2}$ \\ ${ }^{1}$ Department of Botany, D. S. B. Campus, Kumaun University, Nainital, Uttarakhand, India \\ ${ }^{2}$ Applied Microbiology and Biotechnology Laboratory, Department of Botany, University of Delhi, Delhi, India
}

Email address:

mycologistlokendra@gmail.com (L. Singh)

${ }^{*}$ Corresponding author

\section{To cite this article:}

Lokendra Singh, Ved Pal Singh. Decolourization of Azo (Acid Red) and Anthraquinonic (Basic Blue) Dyes by the Fungus Aspergillus flavus. International Journal of Biomedical Engineering and Clinical Science. Vol. 3, No. 1, 2017, pp. 1-5. doi: 10.11648/j.ijbecs.20160301.11

Received: September 18, 2016; Accepted: January 18, 2017; Published: February 18, 2017

\begin{abstract}
Present investigation was carried out to study the fungal decolourization of azo (Acid red) and anthraquinonic (Basic blue) dyes by the fungus Aspergillus flavus. Decolourization of tested dyes was observed visually and studied through spectrophotometric analyses. Growing fungal cultures were filtered through Whatman filter paper No. 1 and filtrates were centrifuged at $6000 \mathrm{rpm}$ for 5 minutes and supernatant was used for spectrophotometric observations, at absorbance $494 \mathrm{~nm}$ and $630 \mathrm{~nm}$, for Acid red and Basic blue dyes, respectively. Decolourization/degradation was recorded by calculating the degradation percentage, using initial and final absorbance of the respective dye. The applied fungal species was found to be able to decolourize the mentioned dyes, as revealed by spectrophotometric analyses which showed a gradual decrease in the initial absorbance and increase in the mycelial yield of the used fungus. Decolourization/ degradation of dye were recorded to be $62 \%$, for Basic blue and $77 \%$ for Acid red.
\end{abstract}

Keywords: Decolourization/Degradation, Azo and Anthraquinonic Dyes, Aspergillus flavus

\section{Introduction}

The dyestuff, textile, paper and leather industries and another major producers and users of dyes, produce effluents that are usually resistant to the biological treatment. The degradation of these industrial wastes, especially the textile wastes, is a major problem to the environment. Textile dyes are mainly classified as azo, diazo, cationic, basic, anthraquinonic and metal complex dyes based on the nature of their chemical structure. Azo dyes constitute a major class of environmental pollutant and known to be highly toxic and mutagenic to the living organisms [1]. Untreated textile effluents and inefficiency of the dyeing process or poor handling of spent effluent for wastes of dyestuff industries lead to dye contamination to the soil and natural water bodies [2]. These dyestuffs affect the photosynthetic activity in aquatic flora by reducing light penetration intensity as well as toxic to aquatic organisms [1]. Mutagenic, carcinogenic and toxic potential of textile effluents have also been extensively studied $[3,4]$.
Current wastewater treatment systems are mainly based on physical and chemical procedures such as absorption, coagulation-flocculation, oxidation, filtration, electrochemical methods. Although these methods are effective, there are also some disadvantages and limitations whereby they suffer from such shortcomings as high cost, formation of hazardous byproducts, operational problems and intensive energy requirements. Therefore, a better and ecofriendly alternative biological process is getting more attention due to its feasibility [5]. The biological processes or microbial treatments have also been suggested to enhance the bio-degradation of textile dyes due the low cost and easy to use [6]. Microbial decolourization and degradation of hazardous dyes and effluents has been in focus to treat the industrial wastes biologically [7]. Therefore, the present investigation was carried out to evaluate the potential of the fungus Aspergillus flavus for decolourization/degradation of Azo (Acid red) and Anthraquinonic (Basic blue). 


\section{Materials and Methods}

\subsection{Microorganisms and Dyes}

The fungus Aspergillus flavus was used for the decolourization of Azo (Acid red) and Anthraquinonic (Basic blue) dyes, which are extensively used in textile industry. Dyes stock solutions (1\%) were prepared separately by dissolving dyes into distilled water.

\subsection{Spore Suspension and Mycelial Dry Weight}

Five to seven days old cultures of fungus A. flavus, grown on Potato Dextrose Agar (PDA, Himedia), were used in the preparation of spores suspension. The spores were harvested in Tween 80 (Sigma-Aldrich) and adjusted to $1 \times 10^{8} / \mathrm{ml}$. Growth was measured in terms of dry weight of mycelium after filtration through Whatman filter paper No. 1 and drying overnight at $80^{\circ} \mathrm{C}$ for 24 hour [8].

\subsection{Medium and Culture Conditions}

Experiments were performed with Potato Dextrose Broth (Himedia). The medium was prepared by dissolving the ingredients in $1 \%$ dye stock solution replacing distilled water and autoclaved at $121^{\circ} \mathrm{C}$ for 16 minutes. Further procedures were followed according to Singh and Singh [8].

\subsection{Monitoring of Dyes Degradation/Decolourization}

Decolourization of dyes were observed visually and measured spectrophotometrically using the Varian Cary 8 Spectrophotometer within the wave length range 250-700 $\mathrm{nm}$, by measuring the absorbance at $494 \mathrm{~nm}$ for Acid red, and $630 \mathrm{~nm}$ for Basic blue. The spectrophotometric measurements were carried out after an interval of 24 hours of incubation following Singh and Singh [8].

\subsection{Percentage of Dyes Degradation/Decolourization}

Percentage of dye decolourization/degradation was calculated according to Awaluddin et al. [9], as:

Percentage of degraded dye $=($ Initial absorbance - Final absorbance/ Initial absorbance) x 100

\subsection{Statistical Analysis}

The statistical analysis were carried out for all experiments and standard deviation (SD) was calculated, and given as mean $\pm \mathrm{SD}$ values in representation [10]. All experiments were done in triplicate under identical conditions.

\section{Results and Discussion}

The results were found positive for the decolourization/degradation of two most used textile dyes; Azo (Acid red) and Anthraquinonic (Basic blue). The applied fungus $A$. flavus was found potent to grow and decolourize the tested dyes in liquid medium. Initially a fast decolourization of dye Acid red was recorded than another tested dye Basic blue (Table 1 and Table 2). During 10 days of growth, higher percentage of dye degradation was recorded for tested dye Acid red that was more than $77 \%$ while it comparatively lower (i.e. 62\%) for another tested anthraquinonic dye, Basic blue (Table 1 and Table 2; Figure 2A). There was a gradual decrease in the initial absorbance for fungal inoculated cultures whereas such changes were not found for un-inoculated or control flasks (Table 1 and Table 2; Figure 1-C1 and $\mathrm{C} 2$ ). Mycelial dry weight increased continuously during the decolourization of tested dyes (Tables 1 and Table 2; Figure 2B).

The data of the growth (mycelial dry weights) along with spectrophotometric analyses for quantitative assessment on dyes decolourization/degradation are summarized in Tables 1 and Table 2. Relying upon the data, it is clear that the applied fungus $A$. flavus was efficient to decolourize the tested dyes, as indicated by the decreased absorbance and increased mycelial weights. Visually a gradual decrease in colour intensity was observed that was found almost directly proportional to the incubation period, as shown in culture filtrates (Figure $1 \mathrm{~A}$ and $\mathrm{B}$ ), and mycelium growth (Figure 2 A and B).

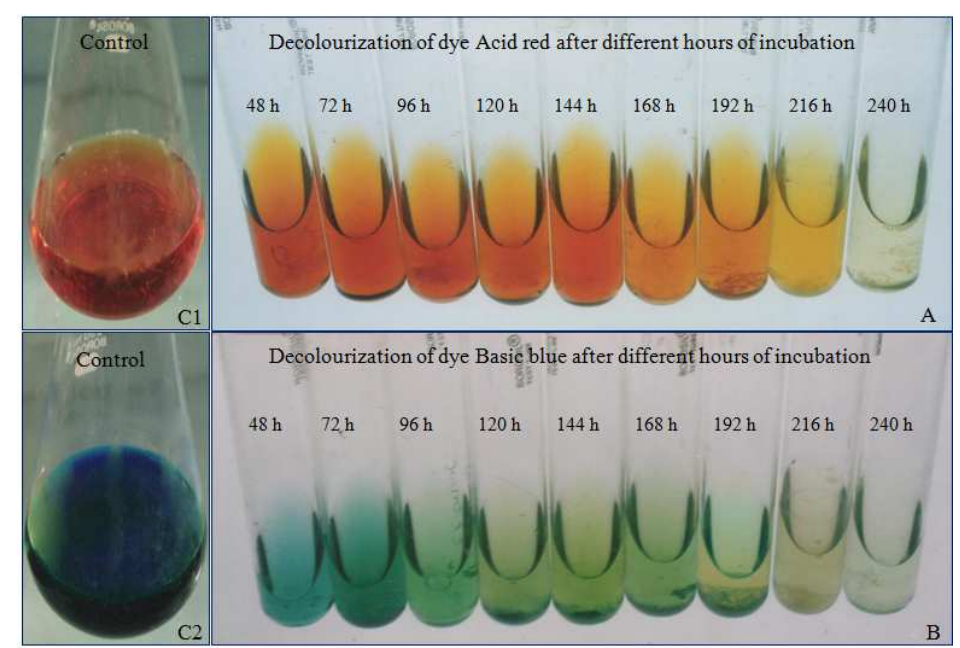

Figure 1. Culture filtrates showing the gradual decolourization/degradation of tested dyes; Acid red (A) and Basic blue (B) after different hours of incubation in respect of their controls $C 1$ and $C 2$, respectively. 
Table 1. Fungal growth and decolourization/degradation of Acid red dye by the fungus A. flavus. Absorbance of control (dye + medium, i.e. initial absorbance) at $494 \mathrm{~nm}$ was $2.066 \pm 0.653$.

\begin{tabular}{llll}
\hline Incubation Time (hrs) & Dry wt. of mycelium $(\mathbf{g m} / \mathbf{4 0 m l})( \pm$ S.D. $)$ & Absorbance of culture filtrate at $\mathbf{6 3 0} \mathbf{~ n m}( \pm$ S.D.) & Percentage of decolourization \\
\hline 24 & $0.16 \pm 0.0050$ & $1.431 \pm 0.0035$ & $30.73 \%$ \\
48 & $0.22 \pm 0.0100$ & $1.350 \pm 0.0200$ & $34.65 \%$ \\
72 & $0.34 \pm 0.0095$ & $1.214 \pm 0.0030$ & $41.23 \%$ \\
96 & $0.39 \pm 0.0081$ & $1.160 \pm 0.0520$ & $43.85 \%$ \\
120 & $0.46 \pm 0.0081$ & $1.061 \pm 0.0490$ & $48.64 \%$ \\
144 & $0.59 \pm 0.0050$ & $1.048 \pm 0.0640$ & $49.27 \%$ \\
168 & $0.74 \pm 0.0095$ & $0.951 \pm 0.0468$ & $53.96 \%$ \\
192 & $0.88 \pm 0.0095$ & $0.739 \pm 0.1040$ & $64.23 \%$ \\
216 & $1.02 \pm 0.0100$ & $0.517 \pm 0.0660$ & $74.97 \%$ \\
240 & $1.12 \pm 0.0100$ & $0.464 \pm 0.0530$ & $77.54 \%$ \\
\hline
\end{tabular}

Table 2. Fungal growth and decolourization/degradation of Basic blue dye by the fungus A. flavus. Absorbance of control (dye + medium, i.e. initial absorbance) at $630 \mathrm{~nm}$ was $3.830 \pm 0.0515$.

\begin{tabular}{llll}
\hline Incubation Time (hrs) & Dry wt. of mycelium $(\mathbf{g m} / \mathbf{4 0 m l}) \mathbf{(} \pm$ S.D.) & Absorbance of culture filtrate at $\mathbf{6 3 0} \mathbf{~ n m}( \pm$ S.D.) & Percentage of decolourization \\
\hline 24 & $0.05 \pm 0.0050$ & $3.718 \pm 0.0170$ & $02.92 \%$ \\
48 & $0.13 \pm 0.0057$ & $3.606 \pm 0.1610$ & $05.84 \%$ \\
72 & $0.29 \pm 0.0050$ & $3.155 \pm 0.0490$ & $17.62 \%$ \\
96 & $0.38 \pm 0.0081$ & $2.266 \pm 0.0490$ & $40.83 \%$ \\
120 & $0.42 \pm 0.0081$ & $2.210 \pm 0.0070$ & $42.29 \%$ \\
144 & $0.53 \pm 0.0050$ & $2.151 \pm 0.0020$ & $43.83 \%$ \\
168 & $0.68 \pm 0.0057$ & $1.707 \pm 0.5110$ & $55.43 \%$ \\
192 & $0.79 \pm 0.0081$ & $1.600 \pm 0.1990$ & $58.22 \%$ \\
216 & $0.84 \pm 0.0100$ & $1.512 \pm 0.1010$ & $60.52 \%$ \\
240 & $0.98 \pm 0.0100$ & $1.450 \pm 0.0190$ & $62.14 \%$ \\
\hline
\end{tabular}
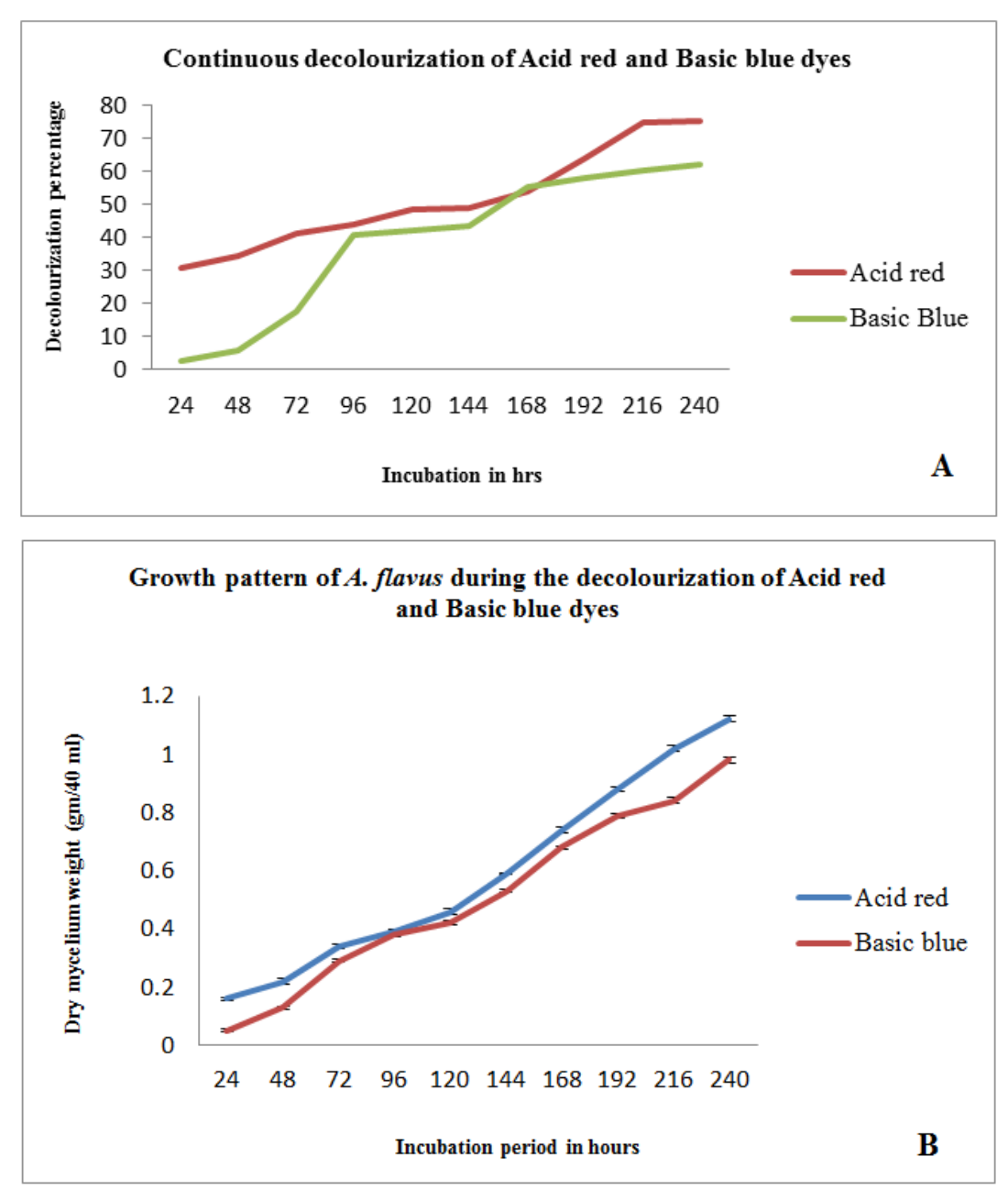

Figure 2. Dyes decolourization/degradation (A) and growth pattern (B) of the fungus A. flavus during the study. 
The results summarized in Table 1 and Table 2, clearly indicates that applied fungus $A$. flavus is positive to degrade/decolourize the tested dyes Acid red and Basic blue. Microbial degradation of Congo red, Bromophenol blue, Acid red and some others textile dyes by the fungi, A. flavus and $T$. harzianum have been studied earlier [11-12,8]. Abadulla et al. [13] reported that the anthraquinonic dyes decolourize faster than the azo dyes by Trametes hirsuta. In the present investigation, comparatively a higher percentage of degradation of azo dye (i.e. $77 \%$, in Table 1) was also recorded. Muthezhilan et al. [14] also found some species of genus Aspergillus, positive for the biodegradation of dyes; Methylene blue, Gentian violet, Crystal violet, Cotton blue, Sudan black, Malachite green and Methyl red, in liquid medium.

The microbial decolourization/degradation of dyes also depend upon the structure of dyes and nature of extracellular enzymes, produced by the involved fungi. Knapp et al. [15] reported that adsorption of dyes to the microbial cell surface is primary mechanism of decolourization. In present investigation, fast degradation of dye Acid red might be due the adsorption of dye through fungal hyphae as well as enzymes production by the applied fungus. Howksworth et al. [16] observed that extracellular radical-generating enzymes by fungi are responsible to decolourize the azo and anthraquinonic dyes. Heinfling et al. [17] found 95\% colour removal of azo and phthalocyanine dyes by Bjerkandera adusta and T. versicolor. In the present study, it was assumed that the decolourization of dyes was due to the adsorption of dyes by the fungal mycelium that is proved by the changed colour of fungus mycelium during the decolourization process in the culture, as it turned into red and blue, in respective dyes. Wong and $\mathrm{Yu}$ [18] also reported the adsorption of Acid green 27, Acid violet 7 and Indigo carmine dyes on living and dead mycelia of Trametes versicolor. Although, dye degrading enzymes were not isolated in the present investigation it is assumed that the rapid and higher decolourization of dyes (Tables 1 and 2; Figures 2) was due to the adsorption of tested dyes as well as involvement dye degrading enzymes that were attributed by the applied fungus A. flavus. Gold et al. [19] reported that fungal extra cellular enzyme manganese peroxidase is actively involved in decolourization. The species of Aspergillus are known to produce dye degrading enzymes, laccase and peroxidase [20-22]. Saranraj et al. [23] reported the degradation of azo dyes and textile effluents by some species of Aspergillus. Vyas and Molitores [24] found that lignin degrading enzymes such as lignin peroxidase (LiP), manganese-dependent peroxidase $(\mathrm{MnP})$ and laccase also decolourize the dyes. Kim and Shoda [25] purified and characterized the novel peroxidase (Dyp) from Geotrichum candidum Dec 1 that is responsible for the dye decolourization. In present study, the increasing fungal biomass may provides a good surface area to absorb the dye contents easily as well as produced fungal enzymes helps in decolourization/degradation of tested dyes in growing cultures of fungus A. flavus. It is also assumed that the growing fungal mycelium was potent enough for the adsorption and to produce sufficient enzymes required for the degradation of tested dyes and shown a higher percentage of dye degradation (Figure 2A).

\section{Conclusion}

However, bacteria also play an important role in the degradation of hazardous dyes but fungi are superior to bacteria, due to adsorption of dyes by their hyphae as well as in the production of dye degrading enzymes [26]. Microbial degradation of hazardous dyes may be a good alternative among the conventional degradation of hazardous dyes and others pollutants.

\section{Acknowledgements}

Authors are thankful to the University of Delhi for providing financial support and necessary facilities. Technical help provided by Mr. S. K. Dass and Mr. Suresh Vig is gratefully acknowledged.

\section{References}

[1] Danesvar N, Ayazloo M, Khataee AR, Pourhassan M (2007) Biological decolorization of dye solution containing Malachite Green by microalgae Cosmarium sp. Biores Tech 98: 1176-1182.

[2] Nigam P, McMullan GM, Banat IM, Merchant R (1996) Decolourization of effluent from the textile industry by a microbial consortium. BiotechnolLett 18: 117-120.

[3] Delclos KB, Tarpley WG, Miller EC, Miller JA (1984) 4aminoazobenzene and N, N-dimethyl-4-amenoazobenzene as equipotent hepatic carcinogens in male $\mathrm{C} 57 \mathrm{BL} / 6 \mathrm{XC} 3 \mathrm{H} / \mathrm{He} \mathrm{F}_{1}$ mice and characterization of $\mathrm{N}$-(deoxyguanosine-8-yl)-4aminoazobenzene as the major persistent hepatic DNA-bound dye in these mice. Canc Res 44: 2540-2550.

[4] Robinson T, McMullan G, Marchant R, Nigam P (2001) Remediation of dyes in textile effluent: a critical review on current treatment technologies with a proposal alternative. Biores Tech 77: 247-255.

[5] Seong JK, Kenichi I, Mitsuyo H, Makoto S (1995) Characteristic of a newly isolated fungus, Geotrichum candidum Dec 1, which decolourize various dyes. J Ferment Bioeng 79 (6): 601-607.

[6] Huag WA, Schmidt B, Nortemann DC, Hempel A, StolzKnackmuss HJ (1991) Mineralization of sulfonated azo dyes mordant yellow 3 by a 6 -aminoaphthalene-2-sulfonate degrading bacterial consortium. Appl Environ Microbiol57: 3144-3149.

[7] Salar RK, Rohilla SK, Rohilla JK (2012) Decolorization of Reactive Black HFGR by Aspergillus sulphureus. Res J Recent Sci1 (1): 55-61.

[8] Singh L, Singh VP (2012) Microbial decolourization of textile dyes by the fungus Trichoderma harzianum. J Pure Appl Microbiol 6 (4): 1829-1833. 
[9] Awaluddin R, Ibrahim D, Ibrahim CO, Uyub AM (2001) Decolourization of commercial available synthetic dyes by the white-rot fungus, Phanerocheate chrysosporium ME446 (ATCC 34541). NSF workshop, Kuala Lumpur, Malaysia.

[10] Mead R, Currow RN (1983) Statistical methods in agricultural and experimental biology. Chapman and Hall, London UK. Pp 335 .

[11] Singh L, Singh VP (2010a) Biodegradation of textile dyes Bromophenol blue and Congo red by the fungus Aspergillus flavus. Environ We Int J Sci Tech 5 (4): 235-242.

[12] Singh L Singh VP (2010b). Microbial degradation and decolourization of dyes in semi-solid medium by the fungus Trichoderma harzianum. Environ We Int J Sci Tech 5 (3): 147-153.

[13] Abadulla E, Tzanov T, Costa S, Robra KH, Cavaco-Paulo A, Gubtiz GM (2000) Decolourization and detoxification of textile dyes with a laccase from Trametes versicolor. Appl Environ Microbiol 66: 3357-3362.

[14] Muthezhilan R, Yoganath N, Vidhya S, Jayalakshmi S (2008) Dye degrading mycoflora from industrial effluents. Res J Microbiol 3 (3): 204-208.

[15] Knapp JS, Newby PS, Recee LP (1995) Decolourization of dyes by wood-rotting basidiomycete fungi. Enzy Microbiol Tech 17: 664-668.

[16] Howksworth DL, Kirk TM, Sutton BC, Pegler DN (1995) Ainsworth and Biesby's dictionary of fungi. CAB International, UK.

[17] Heinfling A, Bergbauer MS (1997) Biodegradation of azo and phthalocyanine dyes by Trametes versicolor and Bjerkandera adusta. Appl Microbiol Biotechnol 48: 261-266.

[18] Wong Y, Yu J (1999) Laccase-catalyzed decolorization of synthetic dyes. Water Res 3: 3512-3520.
[19] Gold MH, Glenn JK, Alic M (1988) Use of polymeric dyes in lignin biodegradation assays. Meth Enzymol161: 74-78.

[20] Berka R, Schneider MP, Golightly EJ, Brown ST, Madden M, Brown K, Halkier MT, Mondorf K, Xu F (1997) Characterization of the gene encoding an extracellular laccase of Myceliophthora thermophila and analysis of the recombinant enzyme expressed in Aspergillus oryzae. Appl Environ Microbiol 63: 3151-3157.

[21] Yever DS, Overjero MDC, Xu F, Nelson BA, Brown KM, Halkier T, Bernauer S, Brown SH, Kauppinen S (1999) Molecular characterization of laccase genes from the basidiomycete Coprinus cinereus and heterologous expression of the laccase Lcc1. Appl Environ Microbiol65: 4943-4948.

[22] Record E, Asther M, Sigoillot C, Pages S (2003) Overproduction of the Aspergillus niger feruloyl esterease for pulp bleaching application. Appl Environ Microbiol62: 349355.

[23] Saranraj P, Sumathi V, Reetha D, Stella D (2010) Fungal decolourization of direct azo dyes and biodegradation of textile dye effluent. J Ecobiotech 7: 12-16.

[24] Vyas BRM, Molitores HP (1995) Involvement of an extracellular $\mathrm{H}_{2} \mathrm{O}_{2}$-dependent lignolytic activity of the white rot fungus Pleurotus ostreatus in the decolorization of Remazol Brilliant Blue R. Appl Environ Microbiol61: 3919_ 3927.

[25] Kim SJ, Shoda M (1999) Purification and characterization of a novel peroxidase from Geotrichum candidum Dec 1, which decolourizes various dyes. J Ferment Bioeng 79: 601-607.

[26] Singh L, Singh VP (2015) Textile dyes degradation: A microbial approach for biodegradation of pollutants. In: Singh SN (ed) Microbial Degradation of Synthetic dyes in Waste waters, Environmental Science and Engineering, Springer International Publishing Switzerland. pp: 187-204. 